\title{
Super-Enhancer Associated Nine-gene Prognostic Score Model for Prediction of Survival in Chronic Lymphoic Leukemia Patients
}

\section{Xue Liang}

Second Affiliated Hospital of Anhui Medical University

\section{Ye Meng}

Second Affiliated Hospital of Anhui Medical University

Cong Li

Second Affiliated Hospital of Anhui Medical University

Yangyang Wang

Second Affiliated Hospital of Anhui Medical University

Lianfang Pu

Second Affiliated Hospital of Anhui Medical University

Linhui Hu

Second Affiliated Hospital of Anhui Medical University

\section{Qian Li}

Second Affiliated Hospital of Anhui Medical University

Zhimin Zhai ( $19965494712 @ 126 . c o m)$

Second Affiliated Hospital of Anhui Medical University https://orcid.org/0000-0003-2772-2110

\section{Research article}

Keywords: chronic lymphocytic leukemia, super-enhancer, prognostic model, overall survival, Lasso

Posted Date: September 30th, 2021

DOI: https://doi.org/10.21203/rs.3.rs-929925/v1

License: (1) (1) This work is licensed under a Creative Commons Attribution 4.0 International License. Read Full License 


\section{Abstract}

\section{Background}

Chronic lymphocytic leukemia (CLL) is a group of highly heterogeneous mature B cell malignancy with various disease courses and diagnoses. Super-enhancer(SE) is a novel concept drew in recent years which is a cluster of enhancers involved in cell differentiation and tumorigenesis, and is one of the promising therapeutic targets for cancer therapy. Although there is a multitude of prognostic markers in $\mathrm{CLL}$, insights into the role of super-enhancer(SE)-related risk indicators are still lacking.

\section{Methods}

The CLL-related super-enhancers in training database were processed by Lasso penalized Cox regression analysis to screen a nine-gene prognostic model. And the associations between all of the individual markers and OS of CLL were assessed by Cox regression analysis. Besides, in order to understand the connection between individual genes and selected disease characteristics, like IGHV mutation status, FISH abnormality, and ZAP70 expression level, we performed correlation analysis.

\section{Results}

A nine-gene prognostic model was screened, including TCF7, VEGFA, MNT, GMIP, SLAMF1, TNFRSF25, GRWD1, SLC6AC, and LAG3. A SE-related risk score was further constructed and the robust predictive performance with 5-year survival and time-to-treatment (TTT) area under the curve(AUC): 0.997 and 1.000 in the training database and 0.628 and 0.673 in the testing database, respectively. Besides, a high correlation was found between the risk score and known prognostic markers of CLL, including the mutational status of immunoglobulin variable region loci (IGHV), chromosomal abnormalities, and ZAP70 expression. Meantime, we noticed that the expression of TCF7, GMIP, SLAMF1, TNFRSF25, and LAG3 in CLL were different from healthy donors $(P<0.01)$, moreover, the risk score and LAG3 level of matched pairs before and after treatment samples varied significantly, although these results were not completely consistent in different datasets.

\section{Conclusion}

Therefore, the SE-associated nine-gene prognostic model developed here may be used to predict the prognosis and assist in the risk stratification of CLL patients in the future.

\section{Background}

Chronic lymphocytic leukemia (CLL), a mature and monoclonal CD5+ CD23+B cell malignancy, proliferates and accumulates in the bone marrow, blood, and lymphoid nodes(1). CLL cases are less in Asia than those in the western world, it is reasonable to assume that genetic and environmental factors play roles in pathogenesis(2). During 2014-2018, the rate of new cases of CLL was 4.9 per 100,000 per year and the median age at diagnosis is 72 years, the death rate was 1.1 (3). 
CLL is widely known as a heterogeneous disease that exhibits variable clinical symptoms, time to treatment(TTT), progression, and prognosis. CLL patients are often diagnosed with incidental findings and the clinical course is ranging from an asymptomatic, indolent disease that requires no treatment to rapidly progressive and chemotherapy-resistant disease until death within a short period(2). The indications for treatment mainly include the clinical stage and symptoms of patients, and the standard therapy is chemoimmunotherapy. Unfortunately, the majority of CLL patients are too old to tolerate intensive standard chemotherapy, therefore, an effective prognostic model is needed to predict the individual clinical courses and to improve the outcome. Over the past few decades, huge advances have been made in figuring out the molecular and genetic biology of CLL to identify the indicators of progression and survival. These indicators include cytogenetics, age, IGHV gene mutation status, $\beta 2$ microglobulin (B2-MG), clinical-stage (RAI/BINET stage), and so forth(4). In CLL, 13q14, 11q22$23 \otimes$ trisomy of $12 q$ and $17 p$ deletions are found in $80 \%$ of the cases. $11 q 22-23$ and $17 p$ deletions are associated with poor survival, whereas $13 q 14$ deletions and trisomy of $12 q$ have a longer TTT and survival time(5). TP53 aberrations(6) indicate a more aggressive disease progression and extensive drugresistant and worse outcome, the same role applies to IGHV genes(7) and ZAP-70(8). Unmutated IGHV and high-expression of ZAP-70 have a comparatively aggressive disease course too, other relevant risk markers include expression of CD38(9), CD49d(9), lipoprotein lipase (LPL)(11), serum concentrations of thymidine kinase(12), and $\beta 2$-microglobulin(13).

Super-enhancer(SE), a new concept proposed for the first time in 2013, is a great cluster of adjacent enhancers that regulates gene expression, affecting cellular identity and the occurrence and progression of tumors. SEs regions include a large number of transcription factors (TFs), co-factors, and enhancerassociated epigenetic modifications(14). Mutation, rearrangement, and inducement of SEs themselves could lead to tumorigenesis and progression. Besides, some novel SEs inhibitors, such as BET inhibitor and CDK7i, which conduct clinical trials, have the potential to improve the tumor cure rate(15). In the hematopoietic system, several mechanisms of tumorigenesis that associated with SEs, including mutation, fusion, and controlling expression of specific genes, signaling pathways related to the tumor, even the infection of EBV.

In this article, a CLL-related SE-associated gene list is used to carry out Lasso penalized Cox regression analysis and construct a nine SE-associated genes prognostic model, namely, TCF7, VEGFA, MNT, GMIP, SLAMF1, TNFRSF25, GRWD1, SLC6AC, and LAG3. Meanwhile, this model is verified by training and testing datasets respectively. Univariate and multivariate Cox regression analysis and ROC curve are analyzed to evaluate the prognostic accuracy of this nine-gene model. Besides the above-validated steps, the role of the nine-gene prognostic model and the nine hub genes are further explored in CLL genesis and the relationship between this prognostic model and other known risk markers, like IGHV status, FISH abnormality, ZAP70 expression level. Finally, paired pre-and post-treatment datasets are used to examine the influences of treatments in the risk score or each nine hub genes expression. It is indicated that the model demonstrats predictive power and has an expected relationship with known risk markers. The improved nine-gene prognostic model of this work provides a bright future for the diagnosis, therapy, and disease stratification of patients with CLL. 


\section{Methods}

\section{Data Source and Microarray Analysis}

The microarray data and clinical data of GSE22762(16) and GSE39671(17) which contain 107 and 130 CLL patients respectively were downloaded from Gene Expression Omnibus (GEO) database. These data were conducted by GPL570 and GPL96/GPL97. Here, 9 other datasets were also analyzed for different purposes, and the details were performed in Table 1(18-24).

\section{Lasso Penalized Cox Regression Analysis}

Super-enhancers-related genes list figured from the Primary B-CLL cell was downloaded from SEA version 3.0 which enriched with a post-translational modification histone mark, H3K27ac ChIP-seq signal. The gene matrix for subsequent analysis was obtained from the overlapping apart of genes in the GSE22762 dataset and the SE-associated genes in the Primary B-CLL cell. For narrowing and selecting the prognostic genes with potentiality, the overlapping gene matrix was weighted by the relative coefficients through the Lasso penalized Cox regression. Ten-fold cross-validation derived the best-fit lambda value to decrease the mean cross-validated error as much as possible via the R package"glmnet". We chose one median parameter to establish one ideal prognosis model. Then we measured time-dependent ROC curves and calculated the area under the ROC (AUC).

\section{Risk Score Model establishment on Predicting Patient Overall Survival}

After Lasso penalized Cox regression analysis was carried out, a risk score model was built using above nine genes, and could calculate a risk score for each sample through this formula: Risk score $=$. Patients were separated into high- and low-risk cohorts (median risk score) using the R software 'survival' and 'survminer' packages and a t-test was used to distinguish death and survival events according to the risk score.

\section{Cox Proportional Hazard Regression Model}

Univariate Cox hazard regression analysis validated the correlation among the expression levels of nine genes and OS of each patient by the R package "survival" and "survminer". At the same time, multivariate Cox hazard regression analyses were performed too. We foresaw the regression coefficient ( $\beta$-value) and $H R$. The $K-M$ survival curve and log-rank test of every single gene was also performed by the R package referred to above.

\section{WGCNA}

Weighted gene co-expression network analysis (WGCNA) screened SE-associated hub genes differentially expressed between healthy donors and CLL patients. We counted out the optimal soft-thresholding value under the scale independence and mean connectivity analysis. CLL-related genes were clustered into 
various modules and gained an intersection of significant models and SE-related gene lists via Venn diagrams.

\section{Gene set enrichment analysis}

Under the standard of risk score, we separated the participants into high- and low-risk group sets. Kyoto Encyclopaedia of Genes and Genomes (KEGG) analysis revealed a potential signaling pathway underlying the two sets via Gene Set Enrichment Analysis (GSEA v4.1.0 software). $p<0.05$ and a false discovery rate $\mathrm{q}<0.25$ were thought to be vital in the statistic.

\section{Statistical analysis}

SPSS software vision 25.0 (SPSS, Inc., Chicago, IL, USA) and R software vision 3.6.3 (R Foundation for Statistical Computing, Vienna, Austria) analyzed the data in statistics. A two-sided $p<0.05$ was thought vital in a statistic.

\section{Results}

\section{Construction and Validation of Nine-gene Lasso Penalized Cox Regression Model}

The flowchart features the construction and validation of the SE-associated gene-based prognostic model of CLL and the correlation with other known risk markers (Figure 1). 831 primary B-CLL cell-related SEs list is downloaded from the website and the 18887 genes matrix in CLL patients is provided in the GSE22762 column and a 587 SE-associated genes matrix for CLL is gained via overlapping above two gene sets. Immediately after, the gene matrix is done by Lasso penalized Cox regression to screen the prognosis-related genes with potentiality. Figure 2A shows the coefficient values for each at various penalty levels. As long as genes with non-zero coefficients has prognostic value in the Lasso penalized regression model. Ten-fold cross-validation obtains the maximum lambda value and we select one model which produced a group of nine genes(Figures 2B). Principal component analysis (PCA) shows high-risk patients separate from low-risk ones evidently (Figure 2C). And the obvious distinction between survival and death is calculated by using the nine gene-based prognostic model, implying that the prognostic model functioned smoothly in the prediction on the OS of patients with CLL (Figure 2D).

\section{Validation of Independent Prognostic Factors by the Cox Regression Model}

To validate the Lasso penalized Cox regression model, univariate Cox proportional hazard regression analysis determines that these genes affect the OS of patients with CLL independently and all log-rank pvalues of the nine genes are $<0.01$ (Figure $3 \mathrm{~A}$ ). Following multivariate Cox proportional hazard regression analysis is performed too, and the global p-value of our model is only 2.64e-16 (Figure 3B), the AIC was 124.96 , and the $\mathrm{C}$-index was 0.95 , these indexes suggest that the nine genes possibly prognostic markers in favor for the OS of CLL patients. Meanwhile, the results of the $\mathrm{K}-\mathrm{M}$ survival analysis show that GRWD1, SLC6A3, MNT have no significant association with survival (Supplement Figure 1). Furthermore, followed above hazard ratio of uni- and multivariate regression analysis, SLAMF1, TCF7, TNFRSF25, 
MNT, and VEGFA are protective factors, whereas GRWD1, SLC6A3, GMIP, and LAG3 appear to be harmful factors in CLL. Thus, the nine-gene SE-associated model by Lasso penalized Cox regression possibly predicts the OS of CLL patients.

\section{Establishment and Validation of the Nine gene-based Risk Score Model}

107 patients in the training dataset of GSE22762 (HGU-133plus2) were divided into high-risk (risk score > 0.7 ) and low-risk groups (risk score < 0.7) (Figure 4A). Figure 4B presents that death is more frequently observed in the high-risk group set than the low-risk group. The $\mathrm{K}-\mathrm{M}$ survival analysis presents a much worse outcome in the high-risk group than that of the low-risk group (log-rank test, p = 3.561e-09) (Figure 4C). And the AUCs of a time-dependent ROC curve of 1-, 3- and 5-year calculated by the nine gene-based risk score model are $0.997,0.958$, and 0.996 respectively (Figure 4D), suggesting that the prediction is highly sensitive and specific. The testing column (GSE22762, N=44, HGU-133A) verifies the predictive values of the nine gene-based risk score. $\mathrm{K}-\mathrm{M}$ curve of high- and low-risk are noticeably different (logrank test, $p<0.05)$, and AUCs of 1-, 3- and 5-year ROC curves are 0.738, 0.679, and 0.628, these results show that this prognostic model might be a potential predictor to judge the OS of patients with CLL (Supplementary Figures 2).

\section{Gene Set Enrichment Analysis}

GSEA is carried out in two datasets on exploring enriched KEGG pathways of which the analysis suggests that vital enrichment is concentrated in the high-risk cohort including base and nucleotide excision repair, DNA replication, and valine-leucine and isoleucine degradation (Figure 5A, B). Other pathways including homologous recombination, oxidative phosphorylation, mismatch repair, RNA degradation, RNA polymerase, and one carbon pool by folate and lysine degradation are enriched in the high-risk group of the two cohorts.

\section{The prediction of the nine-gene model on TTT}

In addition to survival, we also investigate the nine-gene prognostic model on time to treatment (TTT) and the results demonstrate that the nine-gene risk model performs well on predicting TTT in the training data set (GSE22762). Low-risk patients own a longer TTT than high-risk patients and the p-value $<0.001$ (Figure 6A). Additionally, the time-dependent ROC curve analysis prompts that the AUCs of 1-, 3-, and 5-year TTT are $0.818,0.840$, and 1.000 , respectively (Figure 6B). These results are in accordance with testing datasets (GSE39671) (Figure 6C, D), and it indicates that the prognostic model is equally effective in predicting TTT.

\section{Identification of SE-Related Hub Genes in CLL Using WGCNA}

Besides the prognostic value, we also expect there is any relationship between the nine-gene model with tumorigenesis. Weighted gene co-expression network analysis (WGCNA) is another statistical method for the analysis of finding the different genes between normal and CLL patients. As showed in Figure 7A, the best soft-thresholding value via prediction of the scale independence was $\beta=6$. Then, genes were divided 
into 9 different modules with 9 different colors and a heat map was developed according to Pearson's correlation coefficient (Figure 7B). An intersection between the SEs matrix and the nine modules which presented a higher correlation with CLL showed that TCF7 and LAG3 appeared in the interaction genes between module purple, yellow, and SE-associated genes (Figure 7C). Simultaneously, TCF7, GMIP, SLAMF1, TNFRSF25, and LAG3 are found to express differently in normal and CLL patients when we compared the individual expression of nine SE-related hub genes in CLL (Figure 7D). The data indicates that the five genes may play a vital role in regulating the genesis of CLL.

\section{Nine-gene prognostic model and other known risk factors}

The performance of the nine-gene prognostic model is additionally evaluated in different subgroups defined by confirmed risk factors. Patients with mutated IGVH genes, 13q14 or single deletion or trisomy 12 on FISH analysis represent a favorable outcome, whereas patients with unmutated IGVH status, 17p13 or a 11q23 deletions have an unfavorable prognosis. Unmutated IGHV patients have a higher risk score than mutated IGHV patients in three independent datasets (GSE9992, GSE16746 and GSE28654) (Figure $8 \mathrm{~A}-\mathrm{C}$ ). Simultaneously, we analyze the correlation between IGHV mutation status and each gene in the nine-gene prognostic model. The results report that the expression of TCF7 and SLAMF1 has a strong positive correlation, and LAG3 shows a negative correlation with IGHV mutation (Figure 8D). Similarly, patients with del17p13 have a higher risk score compared to other chromosome types $(p<0.001$, Figure 8E). The risk score of ZAP70-high patients is higher than ZAP70-low patients and the expression of MNT and SLAMF1 have a negative association, LAG3 has a positive association with ZAP70 respectively (Figure $8 \mathrm{~F}, \mathrm{G}$ ). Besides, the variation of risk score and each gene expression before and after treatment is provided in Supplement Figure 3A. The risk score is downregulated after processing with HDAC inhibitory in vitro, and VEGFA and MNT are upregulated accompanied by downregulated GMIP and TGFRSF25. In the other two in vivo treatment experiments, no significant change is found except LAG3, the LAG3 gene is upregulated consistently after lenalidomide and thalidomide treatment respectively (Supplement Figure 3B, C).

\section{Disscusion}

Super-enhancer(SE) is a new concept drew in recent years, a growing body of evidence indicates an explicit relationship between increasing tumorigenesis and malignancy of cancer and SEs. SEs drive not only the expression of genes but also non-coding RNA that regulate biological functions directly and indirectly. Lasso penalized Cox regression is popular in recent years cause it could minimize overfitting(25). Hence, in our article, we use this novel bioinformatic strategy and the Cox proportional hazard regression models to screen and optimize hub genes related to survival.

CLL, is considered to have a highly heterogeneous clinical course, with time to first to treatment is varying from months to years, and many patients eventually progressing and requiring chemotherapy, although initially, CLL is reported as an indolent malignancy. A review of the data so far, disease stratification, IGHV mutation status, 17p- and ZAP70 expression are the validated prediction of overall survival. Beyond that, 
gene expression analysis was carried out in various surrogate markers for genetic features and prognosis. Six surface antigens(CD62L, CD54, CD49c,CD49d, CD38, CD79b) prognostic risk model was put in place to diagnose and predict the OS for CLL(26). Besides, some large-scale gene expression profiling analyses generate different prognostic factors $(16,27,28)$. But the before studies constructed no prognostic model according to SEs-associated genes which regulate the expression of hub genes related to CLL tumorigenesis.

In our research, the Lasso penalized Cox regression analysis is carried out by filtering out the potential SEassociated genes and yield a nine-gene prognostic model to foresee the OS of CLL patients. All of the individual markers in the nine-gene model associated with OS of CLL by Cox regression analysis results identical. K-M survival analysis also indicate that the majority of the nine genes correlated to OS. Beyond that, the nine-gene prognostic model is highly significant in the multivariate analysis of patients without treatment. The AUCs and C-index show that our model perform well in the prediction of survival. The effectiveness of this prognostic model could be validated by an independent patient cohort. Besides OS, this risk model is another indicator of TTT. We utilize the Nine-gene risk score in the GSE22762 and GSE39671 dataset and the results also indicate that the nine-gene model could be applied to predict TTT, the high-risk patients had less time to treatment than that of the low-risk. These data strongly indicate that the nine-gene prognostic model is a significant and valid risk forecaster.

We not only evaluate the data by a rigorous training and validation design, but also concentrate on the connection between individual gene and selected disease characteristics, like IGHV mutation status, FISH abnormality, and ZAP70 expression level. The results of three of the markers(TCF7, SLAMF1, and LAG3) are detected according to the association with IGHV status is expected. The lack of a public database that includes both survival data and mutation information limits the further research in a correlation between the nine-gene model and IGHV status. The same situation has occurred in studying ZAP70 and FISH abnormality. But in the poor prognosis group, like ZAP70-high and 17q- patients, the nine-gene risk score is significantly high than the low-risk group and we find that low expression of SLAMF1 in CLL is associated with ZAP70-high expression. The quantitative relation between TCF7, LAG3, and SLAMF1 expression and inferior overall survival is an accurate finding and indicates that these genes have a pathogenic role in CLL. Attended by that, the nine-gene prognostic model also play an important role in CLL etiopathogenesis. The WGCNA of the GSE50006 dataset reveals that TCF7 and LAG3 belonged to two gene module respectively, in addition to this, the expression of GMIP, SLAMF1, and TNFRSF2 5 are also significantly different in normal and CLL patients. Therefore, the five genes contained in our model are possibly functionally vital in the pathogenesis of CLL. In the present study, SLAMF1, TCF7, TNFRSF25, MNT, and VEGFA are protective factors, whereas GRWD1, SLC6A3, GMIP, and LAG3 appear to be harmful factors in CLL, we subsequently discussed each gene in the prognostic model.

Transcription factor 7 (TCF7), the T-cell-specific transcription factor required for T-cell development, animal models, suggested that it probably functions as a tumor suppressor(29). TCF7 over-expression in mice led to a disease resembling CLL, indicating that it was probably involved in the CLL transformation in direct(30). In CLL, TCF7 expression provided a high rate (74\%) of correct assignment of patients at 
genetic risk (IGHV unmutated, V3-21 usage, 11q- or 17p-)(28). The above results are consistent with ours and this indicated TCF7 was an important role in CLL.

Signaling lymphocytic activation molecule family member 1(SLAMF1), also known as CD150), regulates hematopoietic stem cell differentiation, leukocyte adhesion and activation, and humoral immune responses. SLAMF1 comparatively over-express in normal peripheral blood B cells according to before meta-analysis of three gene expressions profiling studies. Recently, researchers found lower levels of SLAMF1 expression in cases with ZAP70-high ( $p<0.001)$, IGHV-unmutated $(p<0.001), 17 q-(p=0.003)$. In past studies, we believed that loss of SLAMF1 expression in CLL modulates genetic pathways regulated chemotaxis and autophagy and that potentially affected drug responses, suggesting that the effects underlie unfavorable clinical outcomes experienced by SLAMF1-low patients(31). Together, SLAMF receptors, the vital modulators of the BCR signaling axis, improve immune control in CLL by interference with NK cells in potential(32). In our research, the univariate and multivariate analysis presented that down-regulated SLAMF1 levels had an independent negative prognostic impact on overall survival $(\mathrm{P}<$ 0.05). We subsequently discovered that SLAMF1 is relatively overexpressed in IGHV mutated and ZAP70low CLL patients. The strict correlation among low levels of it and high-risk genetic features indicated that it probably represented a marker that surrogate genomic complexity, however, mechanism of this correlation is still unknown.

Lymphocyte activating gene 3 (LAG3), the immune inhibitory checkpoint receptor, is one of the immunoglobulin superfamily with about $20 \%$ amino acid homology with CD4. The expression of it activates and exhausts T, NK cells, B cells, dendritic cells, and regulatory T (Treg) cells. LAG3 high expression in CLL cells correlates with unmutated IGHV $(P<0.0001)$ and decreased treatment-free survival $(P=0.0087)(33)$. Increased LAG-3 expression on leukemic cells correlates with shorter time to treatment and poor outcome in CLL, moreover, treatment with relatlimab, a novel anti-LAG-3 blocking monoclonal antibody currently under clinical trial for different solid and hematological malignancies including CLL, restored, at least in part, NK and T cell-mediated anti-tumor responses(34). CART cell generation with the showing of ibrutinib created enhanced cell viability and expansion of CLL patientderived CART cells. And ibrutinib enriched the mentioned cells with the less-differentiated naïve-like phenotype and declined expression of exhaustion markers (PD-1, TIM-3, and LAG-3)(35).

Vascular endothelial growth factor A (VEGFA), a member of the PDGF/VEGF growth factor family. The angiogenesis process makes a significant contribution to the pathogenesis of B-cell chronic lymphocytic leukemia (B-CLL) being the levels of VEGFA and bFGF higher in patients than in healthy(36). Whereas, in our research, VEGFA has a protective role in CLL. High expression of VEGFA indicated a good prognosis by K-M survival analysis, and in normal samples, the level of VEGFA was higher even though it was not statistically significant.

TNF receptor superfamily member 25 (TNFRSF25), the receptor expresses preferentially in the tissues in lymphocytes and possibly functions vital to the regulation of lymphocyte homeostasis. The receptor stimulates sNF-kappa B activity and regulates cell apoptosis. TNFRSF25 was differentially expressed 
activating CLL cells and predominantly detecting in those with early clinical stage disease(37), and probably alters the balance between cell proliferation and death, influencing CLL physiopathology and results in the clinic.

Three genes (GRWD1, GMIP, and SLC6A3) have not been described in the context of CLL before and all of them were upregulated in high-risk CLL patients. The results of the univariate and K-M survival curve were not completely consistent with multivariate analysis. Glutamate rich WD repeat containing 1 (GRWD1), was identified as one of the ribosomal/nucleolar proteins that promote tumorigenesis(38). Meanwhile, GRWD1 was also viewed as having histone-binding activity and regulating chromatin openness to specific chromatin locations(39). Overexpression in colon carcinoma tissues was related to pathological grading, tumor size, N stage, TNM stage, and poor survival, knockdown of GRWD1 function as an inhibitor on cell proliferation and colony formation, and induced cell cycle arrest and more drug susceptibility, and suppressed the migration and invasion(40). GEM interacting protein, a RhoA-specific GAP, in a proteomics screen for proteins interacting with Girdin (Girders of actin), an actin-binding protein critical for neuronal migration to the olfactory bulbs, is identified as one of the major regulators of neuronal migration in the postnatal brain(41). Solute carrier family 6 member 3 (SLC6A3) involving in the metabolism of dopamine and catecholamine is the gene for Parkinson's disease and alcoholism in potentiality. The significance of the above three genes in CLL remained to be further studied.

In GSE14973, the risk score was significantly down-regulated after the valproic acid (VPA) treatment in vitro, meantime, protective factors (VEGFA and MNT) were high-expressed and pathogenic gene (GMIP) was low-expressed than before treatment, except TNFRSF25, and these results were almost consistent with our previous conclusion. VPA, a well-tolerated anti-epileptic drug with HDAC inhibitory activity. HDAC1 and HDAC3 inhibition or knockdown results can be figured out in HDAC7 downregulation which is related to a decline in histone 3 lysine 27 acetylation (H3K27ac) at transcription start sites (TSS) and super-enhancers (SEs) prominently in stem-like BrCa cells. In GSE112953 and GSE15913, the only upregulated gene was LAG3, and it may prompt that combination drug treatment with anti-LAG3 monoclonal antibody would receive a better outcome.

A limited set of gene expression markers was of independent prognostic value and thus increased the accuracy on predicting overall survival and time to treatment, while we couldn't compare the predictions from the model to the individual factors in the clinic, like IGHV somatic mutation status, stage, and other clinical data because of incomplete data; future studies should address this well, and more large cohort studies are needed to validated our model.

\section{Conclusion}

To sum up, it is the initial study using the Lasso model to screen prognostic indicators from the profile of SE-associated genes in CLL. A fruitful prognostic score for OS in untreated CLL patients is presented and the determination on the score can be achieved via the measurement of the expression levels of nine 
genes. It also can do easily in a routine diagnose. In addition, the nine genes in this model are potentially SE-associated genes for CLL, functioning vital in the development and progression of CLL.

\section{Abbreviations}

CLL: Chronic Lymphocytic Leukemia

SE : Super-enhancer

TTT : Time-to-treatment

AUC : Area Under the Curve

IGHV : ImmunoGlobulin Variable region loci

LPL : Lipoprotein Lipase

TFs : Transcription Factors

GEO: Gene Expression Omnibus

WGCNA : Weighted Gene Co-expression Network Analysis

KEGG : Kyoto Encyclopaedia of Genes and Genomes

GSEA : Gene Set Enrichment Analysis

PCA : Principal Component Analysis

TCF7: Transcription Factor 7

SLAMF1: Signaling Lymphocytic Activation Molecule Family member 1

LAG3: Lymphocyte Activating Gene 3

VEGFA : Vascular Endothelial Growth Factor A

TNFRSF25: TNF Receptor Superfamily member 25

GRWD1: Glutamate Rich WD repeat containing 1

GMIP : GEM Interacting Protein

SLC6A3: Solute Carrier family 6 member 3

TSS: Transcription Start Sites 


\section{Declarations}

\section{Ethics approval and consent to participate}

Not applicable.

\section{Consent for publication}

Not applicable.

\section{Availability of data and materials}

Data sharing is not applicable to this article as no datasets were generated or analyzed.

\section{Competing Interests}

All authors declare that they have no conflict of interest.

\section{Funding}

This work was supported by the major subject of science and technology of Anhui province: [grant number 201903a07020030]

\section{Authors' Contributions}

All the authors reviewed and approved the final manuscript.

\section{Acknowledgements}

Not applicable.

\section{References}

1. Hallek M, Shanafelt TD, Eichhorst B. Chronic lymphocytic leukaemia. LANCET. [Journal Article; Review]. 2018 2018-04-14;391(10129):1524-37.

2. Burger JA. Treatment of Chronic Lymphocytic Leukemia. N Engl J Med. [Historical Article; Journal Article; Review]. 2020 2020-07-30;383(5):460-73.

3. The Surveillance Epidemiology and End Results (SEER) Program of the National Cancer Institute. Cancer fact sheets: chronic lymphocytic leukemia (CLL).https://seer.cancer.gov/statfacts/html/clyl.html (accessed Sep 22,2021) .

4. Bosch F, Dalla-Favera R. Chronic lymphocytic leukaemia: from genetics to treatment. NAT REV CLIN ONCOL. [Journal Article; Research Support, N.I.H., Extramural; Research Support, Non-U.S. Gov't; Review]. 2019 2019-11-01;16(11):684-701. 
5. Dohner H, Stilgenbauer S, Benner A, Leupolt E, Krober A, Bullinger L, et al. Genomic aberrations and survival in chronic lymphocytic leukemia. N Engl J Med. [Evaluation Study; Journal Article; Research Support, Non-U.S. Gov't]. 2000 2000-12-28;343(26):1910-6.

6. Zenz T, Eichhorst B, Busch R, Denzel T, Habe S, Winkler D, et al. TP53 mutation and survival in chronic lymphocytic leukemia. J CLIN ONCOL. [Journal Article; Randomized Controlled Trial; Research Support, Non-U.S. Gov't]. 2010 2010-10-10;28(29):4473-9.

7. Damle RN, Wasil T, Fais F, Ghiotto F, Valetto A, Allen SL, et al. Ig V gene mutation status and CD38 expression as novel prognostic indicators in chronic lymphocytic leukemia. BLOOD. [Journal Article; Research Support, Non-U.S. Gov't; Research Support, U.S. Gov't, P.H.S.]. 1999 1999-09-15;94(6):18407.

8. Crespo M, Bosch F, Villamor N, Bellosillo B, Colomer D, Rozman M, et al. ZAP-70 expression as a surrogate for immunoglobulin-variable-region mutations in chronic lymphocytic leukemia. $\mathrm{N}$ Engl J Med. [Journal Article; Research Support, Non-U.S. Gov't]. 2003 2003-05-01;348(18):1764-75.

9. Rassenti LZ, Jain S, Keating MJ, Wierda WG, Grever MR, Byrd JC, et al. Relative value of ZAP-70, CD38, and immunoglobulin mutation status in predicting aggressive disease in chronic lymphocytic leukemia. BLOOD. [Journal Article; Research Support, N.I.H., Extramural]. 2008 2008-0901;112(5):1923-30.

10. Bulian P, Shanafelt TD, Fegan C, Zucchetto A, Cro L, Nuckel H, et al. CD49d is the strongest flow cytometry-based predictor of overall survival in chronic lymphocytic leukemia. J CLIN ONCOL. [Journal Article; Multicenter Study; Research Support, Non-U.S. Gov't]. 2014 2014-03-20;32(9):897904.

11. Prieto D, Oppezzo P. Lipoprotein Lipase Expression in Chronic Lymphocytic Leukemia: New Insights into Leukemic Progression. MOLECULES. [Journal Article; Review]. 2017 2017-12-05;22(12).

12. Hallek M, Langenmayer I, Nerl C, Knauf W, Dietzfelbinger H, Adorf D, et al. Elevated serum thymidine kinase levels identify a subgroup at high risk of disease progression in early, nonsmoldering chronic lymphocytic leukemia. BLOOD. [Journal Article]. 1999 1999-03-01;93(5):1732-7.

13. Hallek M, Wanders L, Ostwald M, Busch R, Senekowitsch R, Stern S, et al. Serum beta(2)microglobulin and serum thymidine kinase are independent predictors of progression-free survival in chronic lymphocytic leukemia and immunocytoma. Leuk Lymphoma. [Comparative Study; Journal Article]. 1996 1996-08-01;22(5-6):439-47.

14. Wang Y, Nie H, He X, Liao Z, Zhou Y, Zhou J, et al. The emerging role of super enhancer-derived noncoding RNAs in human cancer. THERANOSTICS. [Journal Article; Research Support, Non-U.S. Gov't; Review]. 2020 2020-01-20;10(24):11049-62.

15. He Y, Long W, Liu Q. Targeting Super-Enhancers as a Therapeutic Strategy for Cancer Treatment. FRONT PHARMACOL. 2019 2019-01-01;10:361.

16. HEROLD T, JURINOVIC V, SCHMIDBERGER M, SCHMIDT M, SCHNEIDER S, KAKADIA PM, et al. An eight-gene expression signature for the prediction of survival and time to treatment in chronic lymphocytic leukemia. LEUKEMIA. 2011 2011-01-01;25(10):1639-45. 
17. Chuang HY, Rassenti L, Salcedo M, Licon K, Kohlmann A, Haferlach T, et al. Subnetwork-based analysis of chronic lymphocytic leukemia identifies pathways that associate with disease progression. BLOOD. [Journal Article; Research Support, N.I.H., Extramural; Research Support, NonU.S. Gov't; Research Support, U.S. Gov't, Non-P.H.S.]. 2012 2012-09-27;120(13):2639-49.

18. Fabris S, Mosca L, Todoerti K, Cutrona G, Lionetti M, Intini D, et al. Molecular and transcriptional characterization of $17 p$ loss in B-cell chronic lymphocytic leukemia. Genes Chromosomes Cancer. [Journal Article; Research Support, Non-U.S. Gov't]. 2008 2008-09-01;47(9):781-93.

19. Mosca L, Fabris S, Lionetti M, Todoerti K, Agnelli L, Morabito F, et al. Integrative genomics analyses reveal molecularly distinct subgroups of B-cell chronic lymphocytic leukemia patients with 13q14 deletion. CLIN CANCER RES. [Journal Article; Multicenter Study; Research Support, Non-U.S. Gov't]. 2010 2010-12-01;16(23):5641-53.

20. Trojani A, Di Camillo B, Tedeschi A, Lodola M, Montesano S, Ricci F, et al. Gene expression profiling identifies ARSD as a new marker of disease progression and the sphingolipid metabolism as a potential novel metabolism in chronic lymphocytic leukemia. CANCER BIOMARK. [Journal Article; Research Support, Non-U.S. Gov't]. 2011 2011-01-20;11(1):15-28.

21. Herold T, Jurinovic V, Mulaw M, Seiler T, Dufour A, Schneider $S$, et al. Expression analysis of genes located in the minimally deleted regions of 13q14 and 11q22-23 in chronic lymphocytic leukemiaunexpected expression pattern of the RHO GTPase activator ARHGAP20. Genes Chromosomes Cancer. [Journal Article; Research Support, Non-U.S. Gov't]. 2011 2011-07-01;50(7):546-58.

22. Stamatopoulos B, Haibe-Kains B, Equeter C, Meuleman N, Soree A, De Bruyn C, et al. Gene expression profiling reveals differences in microenvironment interaction between patients with chronic lymphocytic leukemia expressing high versus low ZAP70 mRNA. HAEMATOLOGICA. [Journal Article; Research Support, Non-U.S. Gov't]. 2009 2009-06-01;94(6):790-9.

23. Stamatopoulos B, Meuleman N, De Bruyn C, Mineur P, Martiat P, Bron D, et al. Antileukemic activity of valproic acid in chronic lymphocytic leukemia $B$ cells defined by microarray analysis. LEUKEMIA. [Journal Article; Research Support, Non-U.S. Gov't]. 2009 2009-12-01;23(12):2281-9.

24. Giannopoulos K, Dmoszynska A, Kowal M, Wasik-Szczepanek E, Bojarska-Junak A, Rolinski J, et al. Thalidomide exerts distinct molecular antileukemic effects and combined thalidomide/fludarabine therapy is clinically effective in high-risk chronic lymphocytic leukemia. LEUKEMIA. [Journal Article; Research Support, Non-U.S. Gov't]. 2009 2009-10-01;23(10):1771-8.

25. Ma H, Qu J, Luo J, Qi T, Tan H, Jiang Z, et al. Super-Enhancer-Associated Hub Genes In Chronic Myeloid Leukemia Identified Using Weighted Gene Co-Expression Network Analysis. CANCER MANAG RES. [Journal Article]. 2019 2019-01-20;11:10705-18.

26. Zucchetto A, Bomben R, Dal Bo M, Sonego P, Nanni P, Rupolo M, et al. A scoring system based on the expression of six surface molecules allows the identification of three prognostic risk groups in B-cell chronic lymphocytic leukemia. J CELL PHYSIOL. [Journal Article; Research Support, Non-U.S. Gov't]. 2006 2006-05-01;207(2):354-63. 
27. Schweighofer CD, Coombes KR, Barron LL, Diao L, Newman RJ, Ferrajoli A, et al. A two-gene signature, SKI and SLAMF1, predicts time-to-treatment in previously untreated patients with chronic lymphocytic leukemia. PLOS ONE. [Journal Article; Research Support, N.I.H., Extramural; Research Support, Non-U.S. Gov't]. 2011 2011-01-20;6(12):e28277.

28. Kienle D, Benner A, Laufle C, Winkler D, Schneider C, Buhler A, et al. Gene expression factors as predictors of genetic risk and survival in chronic lymphocytic leukemia. HAEMATOLOGICA. [Comparative Study; Journal Article; Research Support, Non-U.S. Gov't]. 2010 2010-01-01;95(1):102-9.

29. Roose J, Huls G, van Beest M, Moerer P, van der Horn K, Goldschmeding R, et al. Synergy between tumor suppressor APC and the beta-catenin-Tcf4 target Tcf1. SCIENCE. [Journal Article]. 1999 199909-17;285(5435):1923-6.

30. Bichi R, Shinton SA, Martin ES, Koval A, Calin GA, Cesari R, et al. Human chronic lymphocytic leukemia modeled in mouse by targeted TCL1 expression. Proc Natl Acad Sci U S A. [Journal Article; Research Support, Non-U.S. Gov't; Research Support, U.S. Gov't, P.H.S.]. 2002 2002-0514;99(10):6955-60.

31. Bologna C, Buonincontri R, Serra S, Vaisitti T, Audrito V, Brusa D, et al. SLAMF1 regulation of chemotaxis and autophagy determines CLL patient response. J CLIN INVEST. [Journal Article; Research Support, Non-U.S. Gov't]. 2016 2016-01-01;126(1):181-94.

32. von Wenserski L, Schultheiss C, Bolz S, Schliffke S, Simnica D, Willscher E, et al. SLAMF receptors negatively regulate $B$ cell receptor signaling in chronic lymphocytic leukemia via recruitment of prohibitin-2. LEUKEMIA. [Journal Article; Research Support, Non-U.S. Gov't]. 2021 2021-0401;35(4):1073-86.

33. Kotaskova J, Tichy B, Trbusek M, Francova HS, Kabathova J, Malcikova J, et al. High expression of lymphocyte-activation gene 3 (LAG3) in chronic lymphocytic leukemia cells is associated with unmutated immunoglobulin variable heavy chain region (IGHV) gene and reduced treatment-free survival. J MOL DIAGN. [Journal Article; Research Support, Non-U.S. Gov't]. 2010 2010-0501;12(3):328-34.

34. Sordo-Bahamonde C, Lorenzo-Herrero S, Gonzalez-Rodriguez AP, Payer AR, Gonzalez-Garcia E, LopezSoto A, et al. LAG-3 Blockade with Relatlimab (BMS-986016) Restores Anti-Leukemic Responses in Chronic Lymphocytic Leukemia. Cancers (Basel). [Journal Article]. 2021 2021-04-27;13(9).

35. Fan F, Yoo HJ, Stock S, Wang L, Liu Y, Schubert ML, et al. Ibrutinib for improved chimeric antigen receptor T-cell production for chronic lymphocytic leukemia patients. INT J CANCER. [Journal Article; Research Support, Non-U.S. Gov't]. 2021 2021-01-15;148(2):419-28.

36. Ballester S, Pineda B, Rodrigues P, Tormo E, Terol MJ, Eroles P. Clinical Relevance of +936 C>T VEGFA and c.233C>T bFGF Polymorphisms in Chronic Lymphocytic Leukemia. Genes (Basel). [Journal Article; Research Support, Non-U.S. Gov't]. 2020 2020-06-23;11(6).

37. Cavallini C, Lovato O, Bertolaso A, Zoratti E, Malpeli G, Mimiola E, et al. Expression and function of the TL1A/DR3 axis in chronic lymphocytic leukemia. Oncotarget. [Comparative Study; Journal Article; Research Support, Non-U.S. Gov't]. 2015 2015-10-13;6(31):32061-74. 
38. Takafuji T, Kayama K, Sugimoto N, Fujita M. GRWD1, a new player among oncogenesis-related ribosomal/nucleolar proteins. CELL CYCLE. [Journal Article; Review]. 2017 2017-08-03;16(15):1397403.

39. Sugimoto N, Maehara K, Yoshida K, Yasukouchi S, Osano S, Watanabe S, et al. Cdt1-binding protein GRWD1 is a novel histone-binding protein that facilitates MCM loading through its influence on chromatin architecture. NUCLEIC ACIDS RES. [Journal Article; Research Support, Non-U.S. Gov't]. 2015 2015-07-13;43(12):5898-911.

40. Zhou X, Shang J, Liu X, Zhuang JF, Yang YF, Zhang YY, et al. Clinical Significance and Oncogenic Activity of GRWD1 Overexpression in the Development of Colon Carcinoma. Onco Targets Ther. [Journal Article]. 2021 2021-01-20;14:1565-80.

41. Ota H, Hikita T, Sawada M, Nishioka T, Matsumoto M, Komura M, et al. Speed control for neuronal migration in the postnatal brain by Gmip-mediated local inactivation of RhoA. NAT COMMUN. [Journal Article; Research Support, Non-U.S. Gov't]. 2014 2014-07-30;5:4532.

\section{Tables}

Table 1. The details of databases used in this research. 


\begin{tabular}{|c|c|c|c|c|}
\hline $\begin{array}{l}\text { GEO } \\
\text { accession }\end{array}$ & Number & $\begin{array}{l}\text { subgroup of } \\
\text { samples }\end{array}$ & Sample type & application in article \\
\hline GSE22762[15] & 151 & $151 \mathrm{CLL}$ & PBMC & $\begin{array}{l}\text { Establishment of survival } \\
\text { model by Lasso and } \\
\text { survival analysis of OS and } \\
\text { TTT by nine-gene model }\end{array}$ \\
\hline GSE39671[16] & 130 & 130 CLL & PBMC & $\begin{array}{l}\text { survival analysis of TTT by } \\
\text { nine-gene model }\end{array}$ \\
\hline \multirow[t]{2}{*}{ GSE50006 } & \multirow[t]{2}{*}{210} & 188 CLL & \multirow[t]{2}{*}{ CD19+ B cells } & \multirow{2}{*}{$\begin{array}{l}\text { Validation for expression } \\
\text { diference of hub genes } \\
\text { between CLL and healthy } \\
\text { dornors }\end{array}$} \\
\hline & & $\begin{array}{l}32 \text { healthy } \\
\text { donors }\end{array}$ & & \\
\hline \multirow[t]{2}{*}{ GSE9992[17] } & \multirow[t]{2}{*}{60} & $24 \mathrm{M}-\mathrm{CLL}$ & \multirow{2}{*}{$\begin{array}{l}\text { CD } 5+C D 19+C D 23+ \\
\text { B cells }\end{array}$} & \multirow{2}{*}{$\begin{array}{l}\text { Validation for the correlation } \\
\text { of hub gene expression and } \\
\text { risk score with IGHV status }\end{array}$} \\
\hline & & 36 U-CLL & & \\
\hline \multirow[t]{2}{*}{ GSE16746[18] } & \multirow[t]{2}{*}{60} & $23 \mathrm{M}-\mathrm{CLL}$ & \multirow{2}{*}{$\begin{array}{l}\text { CD 5+CD19+CD23+ } \\
\text { B cells }\end{array}$} & \multirow{2}{*}{$\begin{array}{l}\text { Validation for the correlation } \\
\text { of hub gene expression and } \\
\text { risk score with IGHV status }\end{array}$} \\
\hline & & 37 U-CLL & & \\
\hline \multirow[t]{2}{*}{ GSE28654[19] } & \multirow[t]{2}{*}{89} & $61 \mathrm{M}-\mathrm{CLL}$ & \multirow[t]{2}{*}{ CD19+ cells } & \multirow{2}{*}{$\begin{array}{l}\text { Validation for the correlation } \\
\text { of hub gene expression and } \\
\text { risk score with IGHV status }\end{array}$} \\
\hline & & 28 U-CLL & & \\
\hline GSE25571[20] & 109 & FISH abnormality & PBMC & $\begin{array}{l}\text { Validation for the correlation } \\
\text { of hub gene expression and } \\
\text { risk score with genotypic } \\
\text { abnormality }\end{array}$ \\
\hline \multirow[t]{2}{*}{ GSE12734[21] } & \multirow[t]{2}{*}{14} & 7 high-ZAP70 & \multirow[t]{2}{*}{ CD19+ cells } & \multirow{2}{*}{$\begin{array}{l}\text { Validation for the correlation } \\
\text { of hub gene expression and } \\
\text { risk score with ZAP70 } \\
\text { expression level }\end{array}$} \\
\hline & & 7 low-ZAP70 & & \\
\hline GSE14973[22] & 28 & $\begin{array}{l}14 \text { CLL with and } \\
\text { without VPA }\end{array}$ & B cells & $\begin{array}{l}\text { Validation for the correlation } \\
\text { of hub gene expression and } \\
\text { risk score with before and } \\
\text { after treatment }\end{array}$ \\
\hline GSE112953 & 22 & $\begin{array}{l}11 \text { CLL before } \\
\text { and after } \\
\text { Lenalidomide } \\
\text { treatment }\end{array}$ & CD19+ cells & $\begin{array}{l}\text { Validation for the correlation } \\
\text { of hub gene expression and } \\
\text { risk score with before and } \\
\text { after treatment }\end{array}$ \\
\hline GSE15913[23] & 40 & $\begin{array}{l}20 \text { CLL before } \\
\text { and after } \\
\text { thalidomide } \\
\text { treatment }\end{array}$ & PBMC & $\begin{array}{l}\text { Validation for the correlation } \\
\text { of hub gene expression and } \\
\text { risk score with before and } \\
\text { after treatment }\end{array}$ \\
\hline
\end{tabular}

CLL, Chronic lymphocytic leukemia; PBMC, peripheral blood mononuclear cells; M-CLL, IGHV mutated CLL; U-CLL, IGHV un-mutated CLL; OS, overall survival; TTT, time-to -treatment 


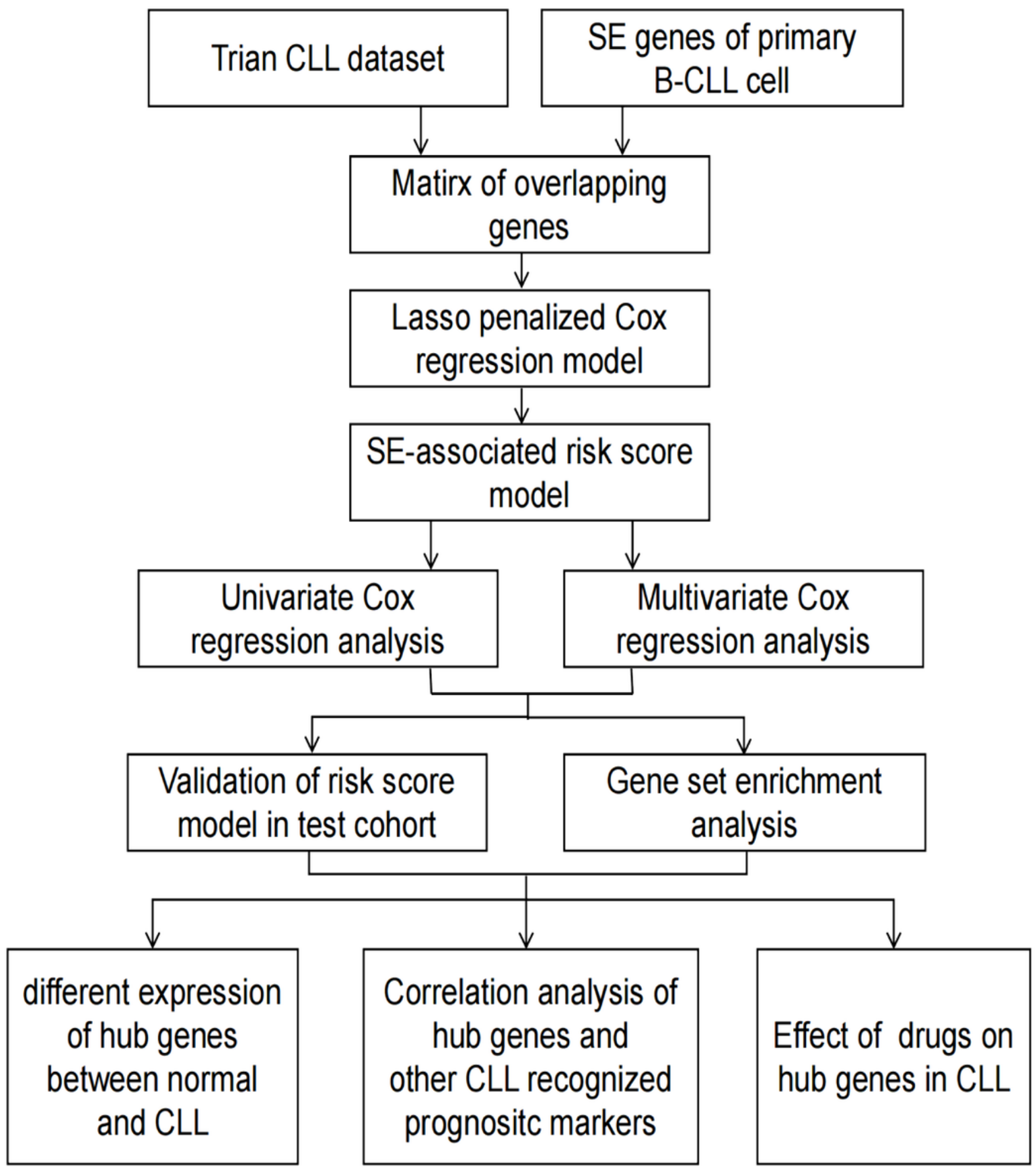

Figure 1

A flowchart of the overall procedure used to establish and verify the SE-associated gene-based prognostic model in CLL patients. 

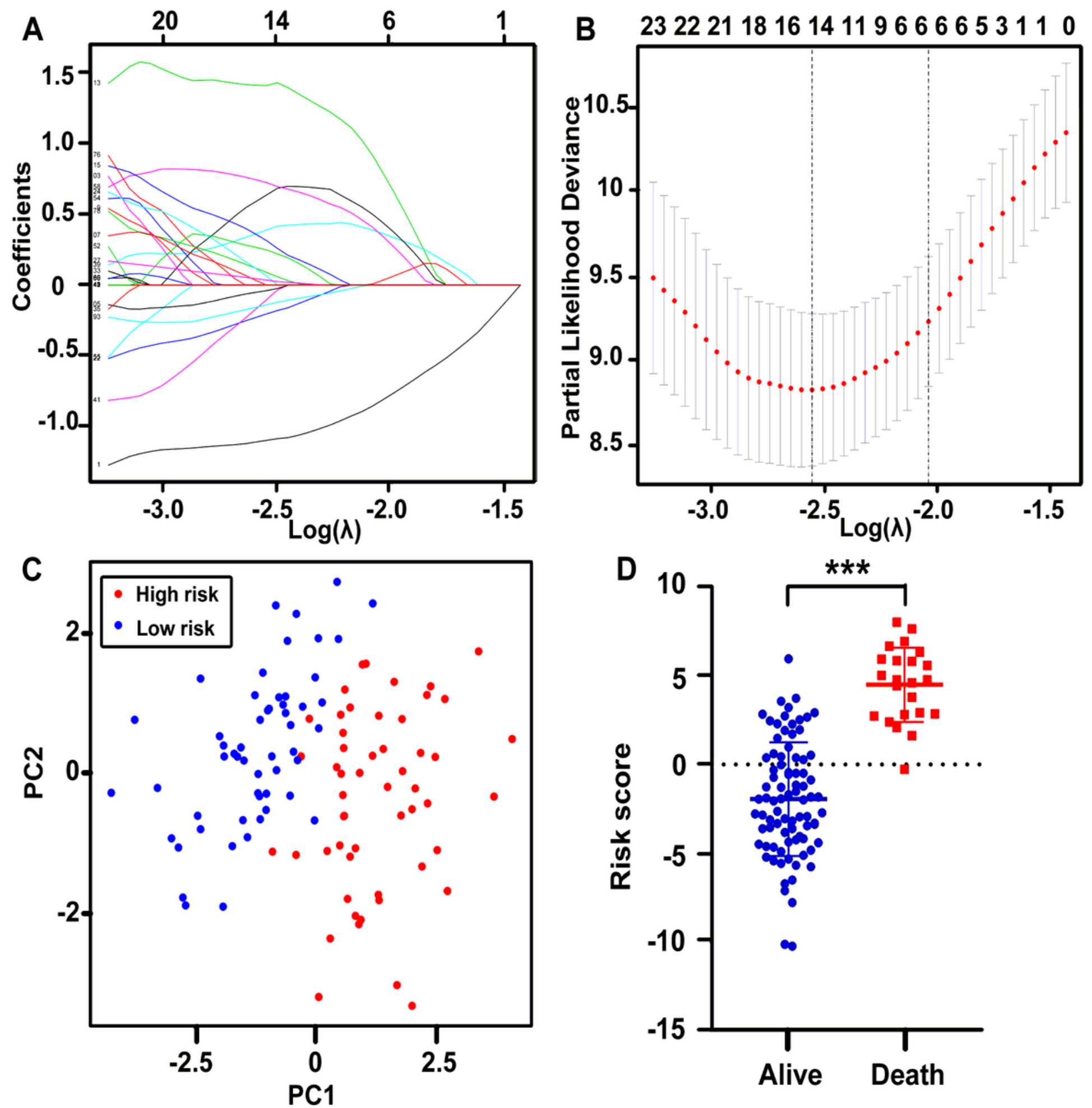

Figure 2

Construction of the SE-related prognostic model. (A) The lasso coefficient values at various levels of penalty, each curve represents a SE-gene. (B) The comfirmation of the best lambda value by lasso Cox regression analysis. (C) Principle component analysis(PCA), red dots correspond to high risk patients, blue dots correspond to low risk patients. (D) The scatter plot of survival status of CLL patients based on 9-genes model using the t-test. ${ }^{\star \star \star}$. $p<0.001$. 


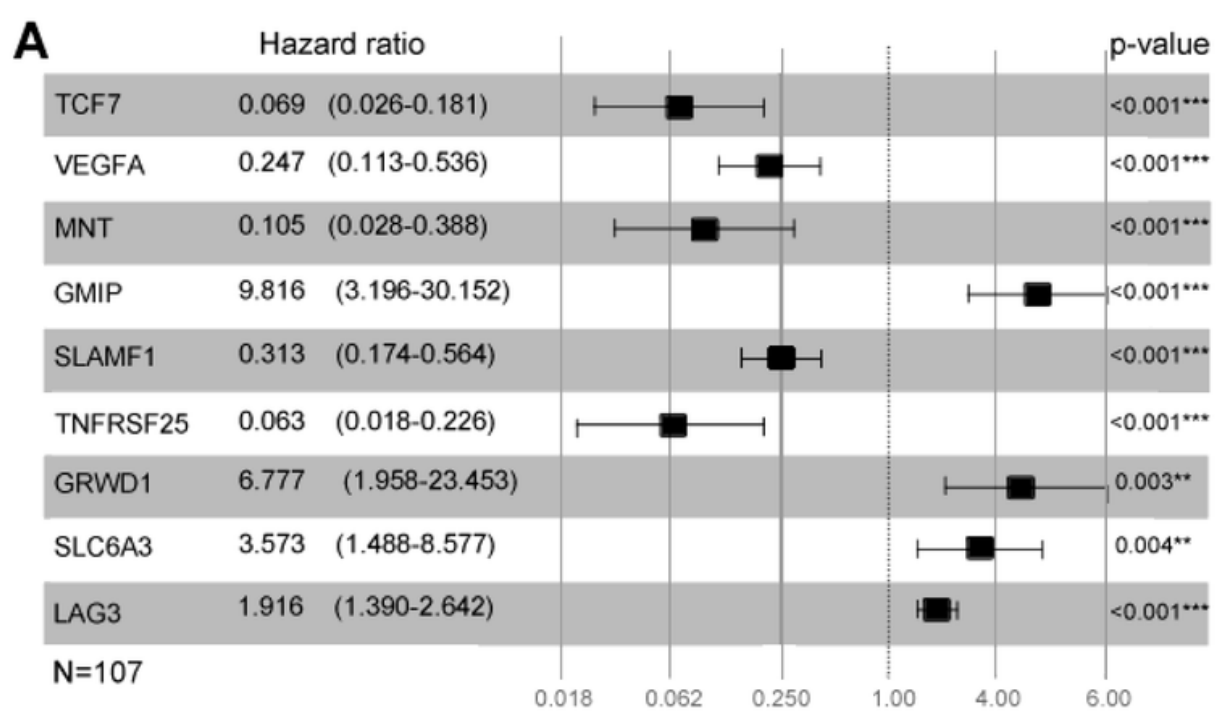

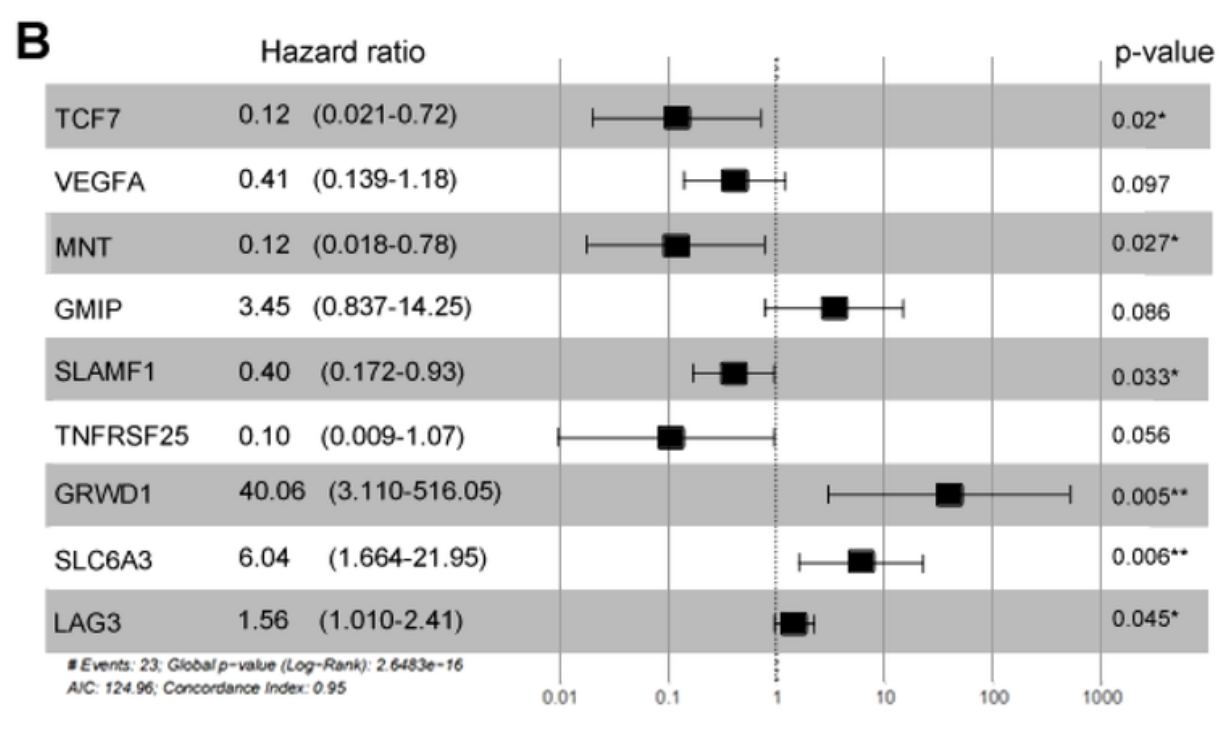

\section{Figure 3}

Univariate and multivariate Cox regression analyses of the SE-related nine-gene prognostic model. (A) Univariate Cox regression analysis of the each gene of the model. (B) Multivariate Cox regression analysis of the nine-gene model. ${ }^{*},<0.05, * *, p<0.01, * \star *, p<0.001$. 

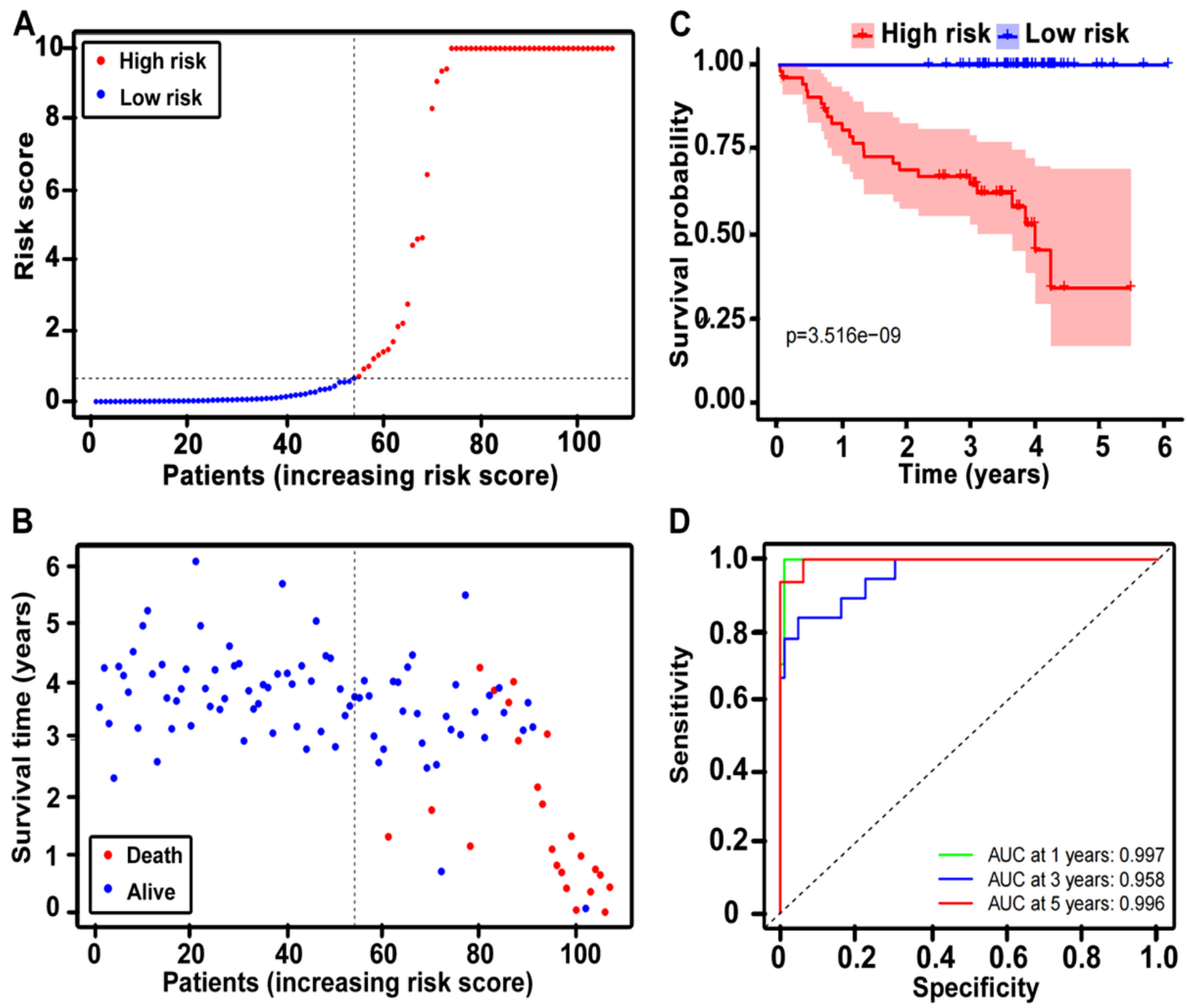

Figure 4

The nine-gene prognostic model for the GSE22762 dataset (N=107, HG-U133_Plus_2). (A) Dot plots comparing outcomes of subjects in the high- and low-risk cohorts. (B) The survival status and time in high- and low-risk group. (C) K-M survival curves showing the difference between high- and low-risk group. (D) Time dependent ROC curve analysis for the prediction survival using the nine-gene model. K-M, Kaplan-Meier; ROC, receiver operating characteristic; AUC, area under the curve. 

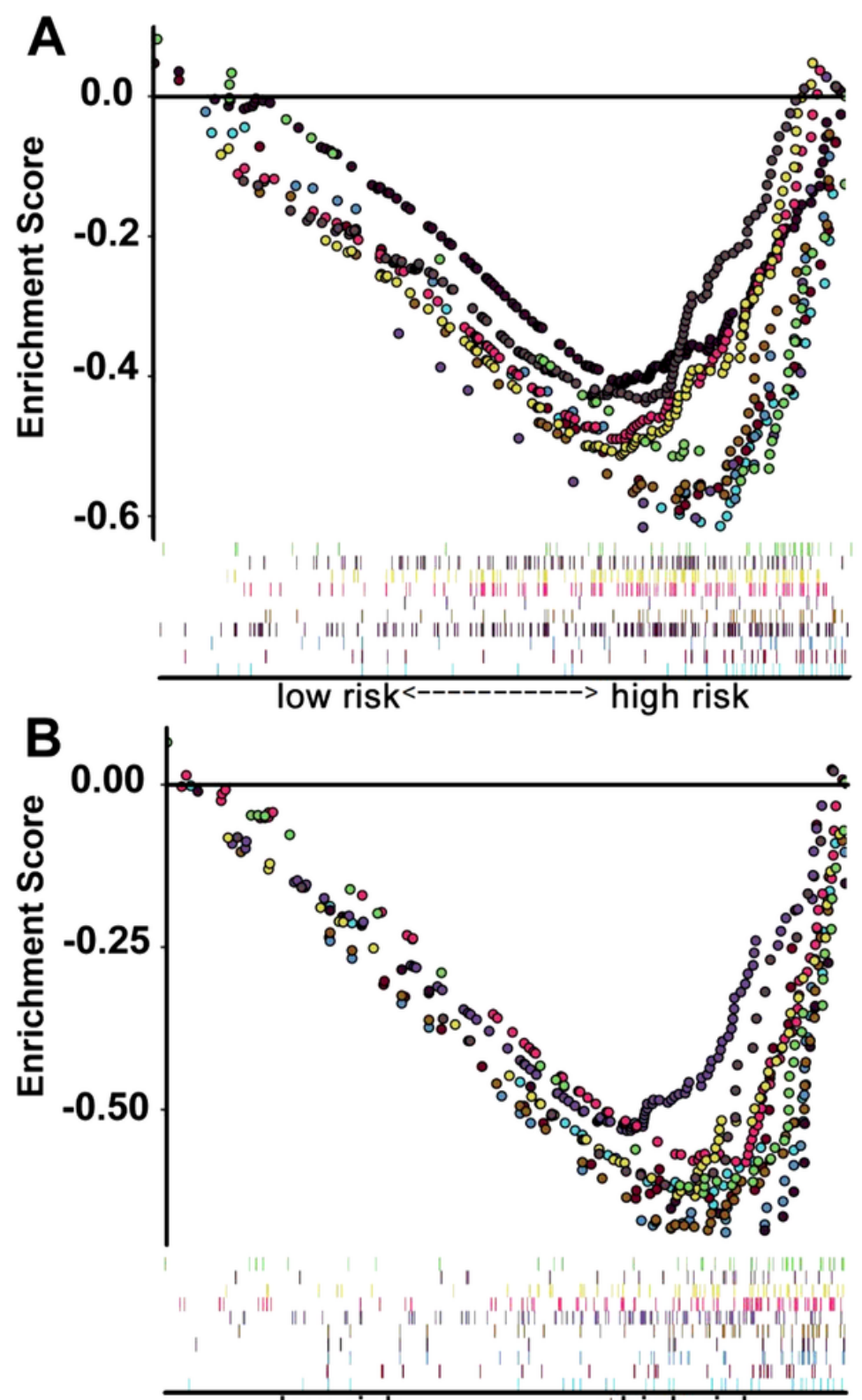

low risk <------------> high risk
- BASE EXCISION REPAIR

- DNA REPLICATION

- HOMOLOGOUS RECOMBINATION

- HUNTINGTONS DISEASE

- NUCLEOTIDE EXCISION REPAIR

- ONE CARBON POOL BY FOLATE

- OXIDATIVE PHOSPHORYLATION

- PARKINSONS DISEASE

- SPLICEOSOME

- VALINE LEUCINE AND ISOLEUCINE DEGRADATION
- BASE EXCISION REPAIR

- CITRATE CYCLE TCA CYCLE

- DNA REPLICATION

- MISMATCH REPAIR

- NUCLEOTIDE EXCISION REPAIR

- PARKINSONS DISEASE

- PEROXISOME

- RNA DEGRADATION

- RNA POLYMERASE

- VALINE LEUCINE AND ISOLEUCINE DEGRADATION

Figure 5

Pathways with significant enrichment in each dataset. The top 10 pathways were enriched in the training dataset $(A)$ and validation cohorts (B). 

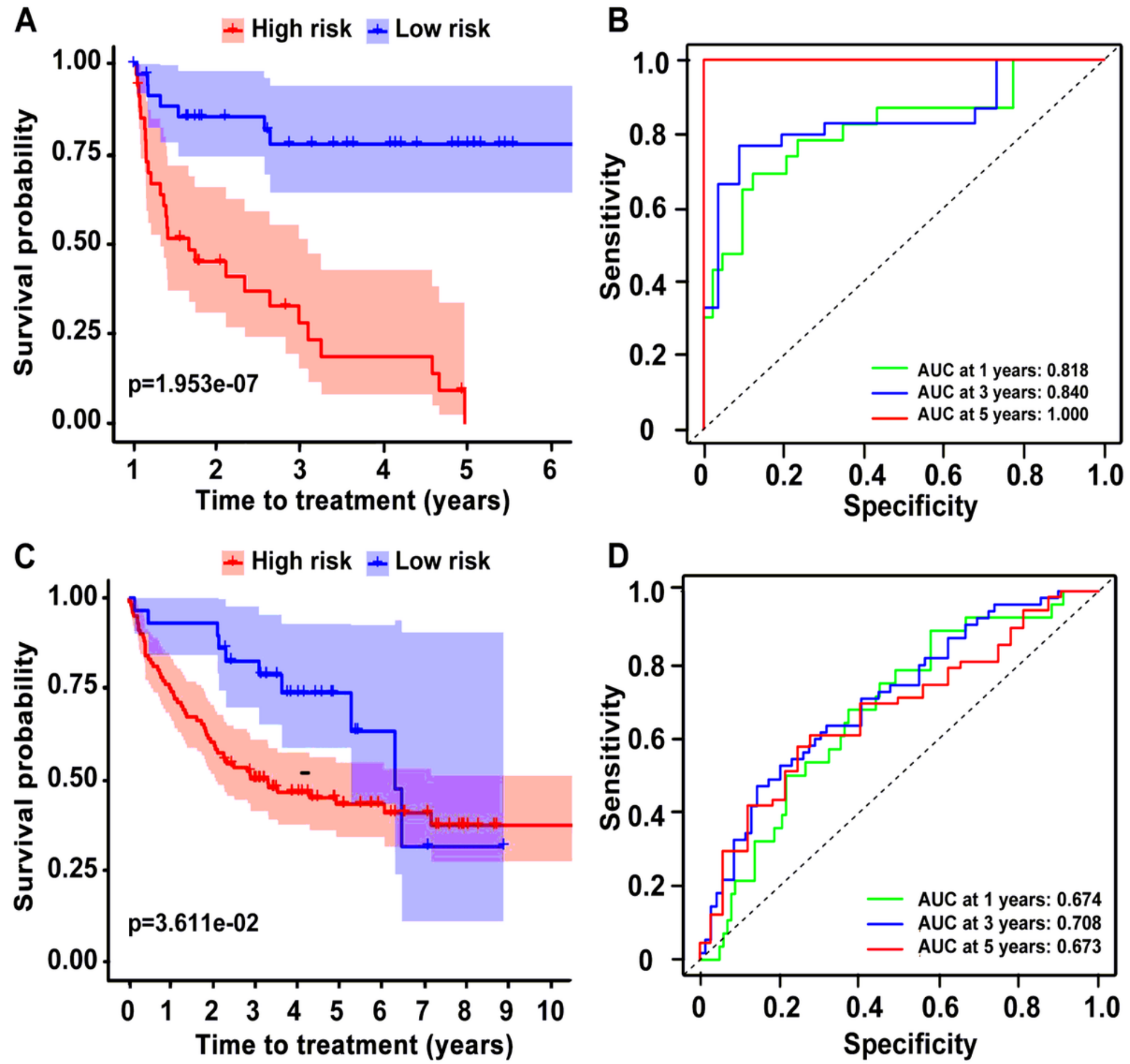

Figure 6

The prediction of TTT on CLL patients. (A)(C) K-M survival curves showing the different TTT on two datasets and (B)(D) ROC analysis for the prediction of TTT. 


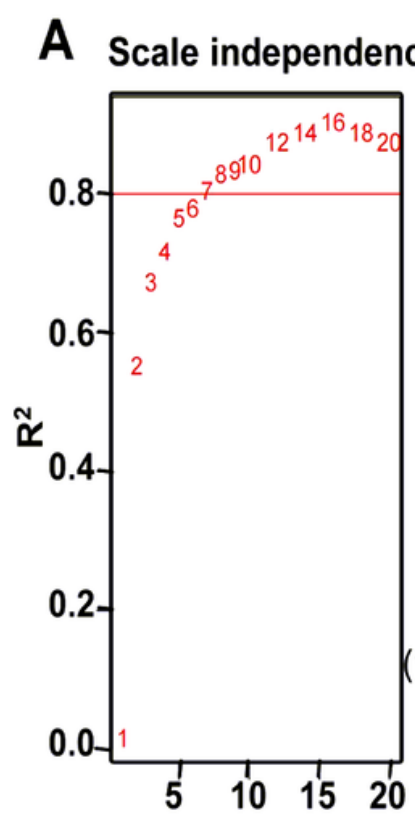

Soft threshold (power)
Mean connectivity

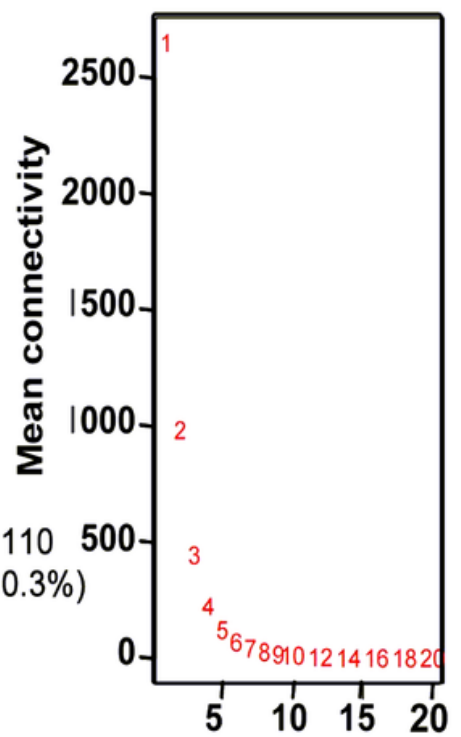

Soft threshold (power)
B

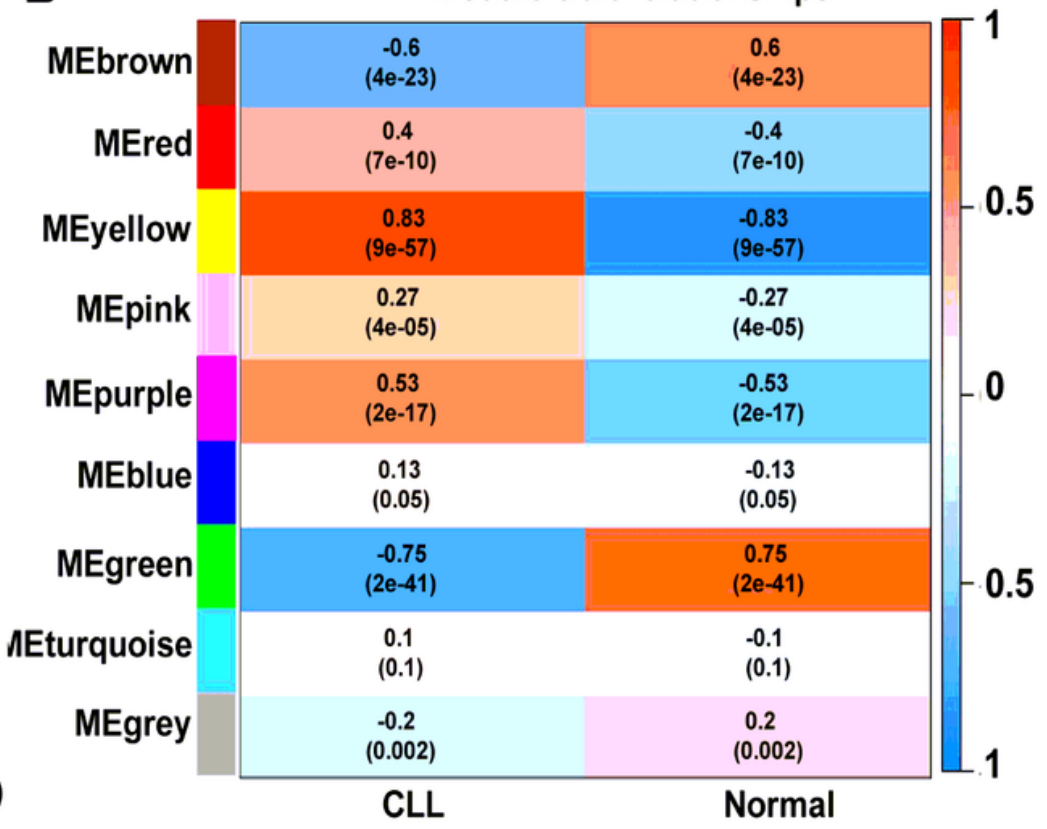

Normal
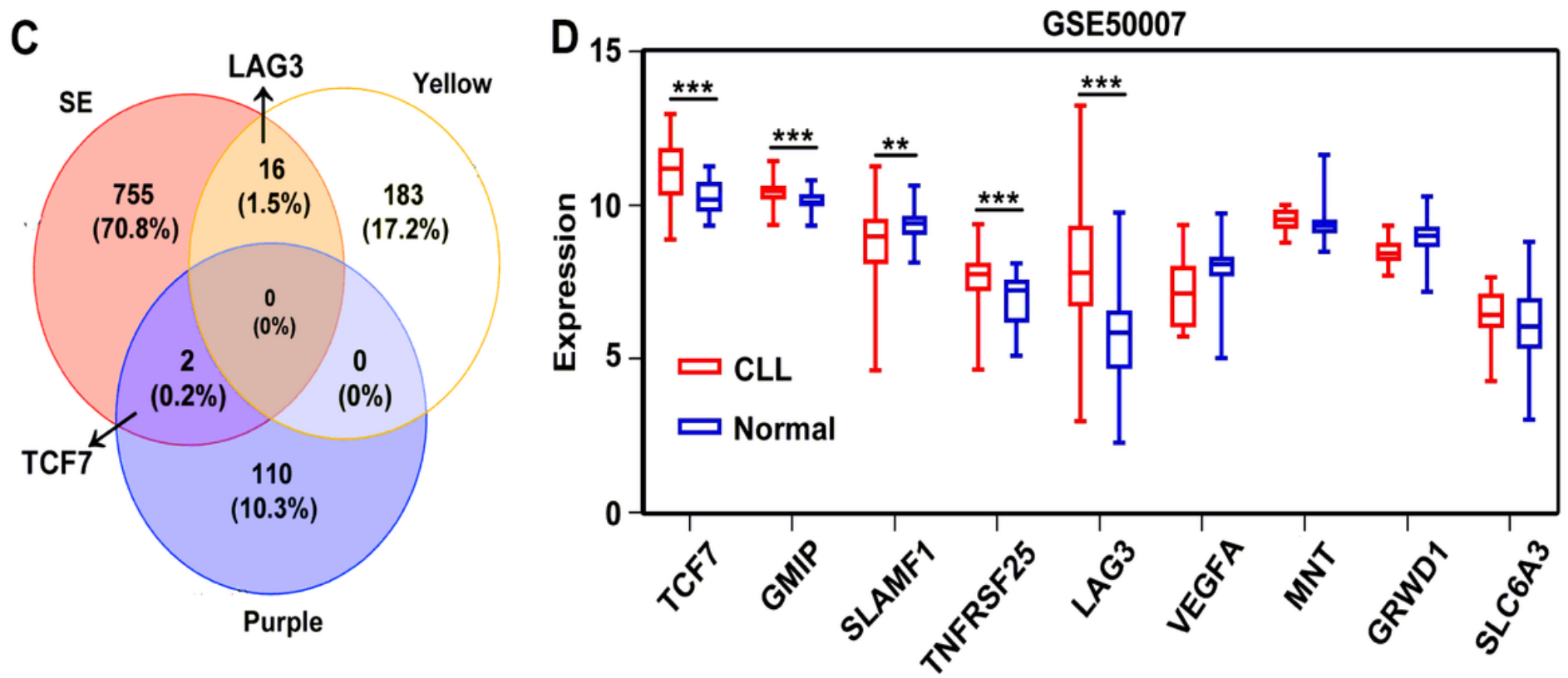

Figure 7

Identification of SE-related hub gene in CLL based on GSE50006 dataset through WGCNA analysis.(A) Analysis of the scale independence and mean connectivity (vertical axis) for various soft-thresholding powers( $\beta$ value of horizontal axis). (B)(C) Heatmap of the correlation between modules and CLL. The yellow and purple module had a high correlation with CLL patients and the $p$-value in the table specified the correlation. TCF7 and LAG3 appeared in the intersection of SE-related genes and the two modules, respectively. (D) The nine hub genes expression was significantly different between normal and CLL patients in GSE50006 dataset. **, $p<0.01 ; * \star \star, p<0.001$. 

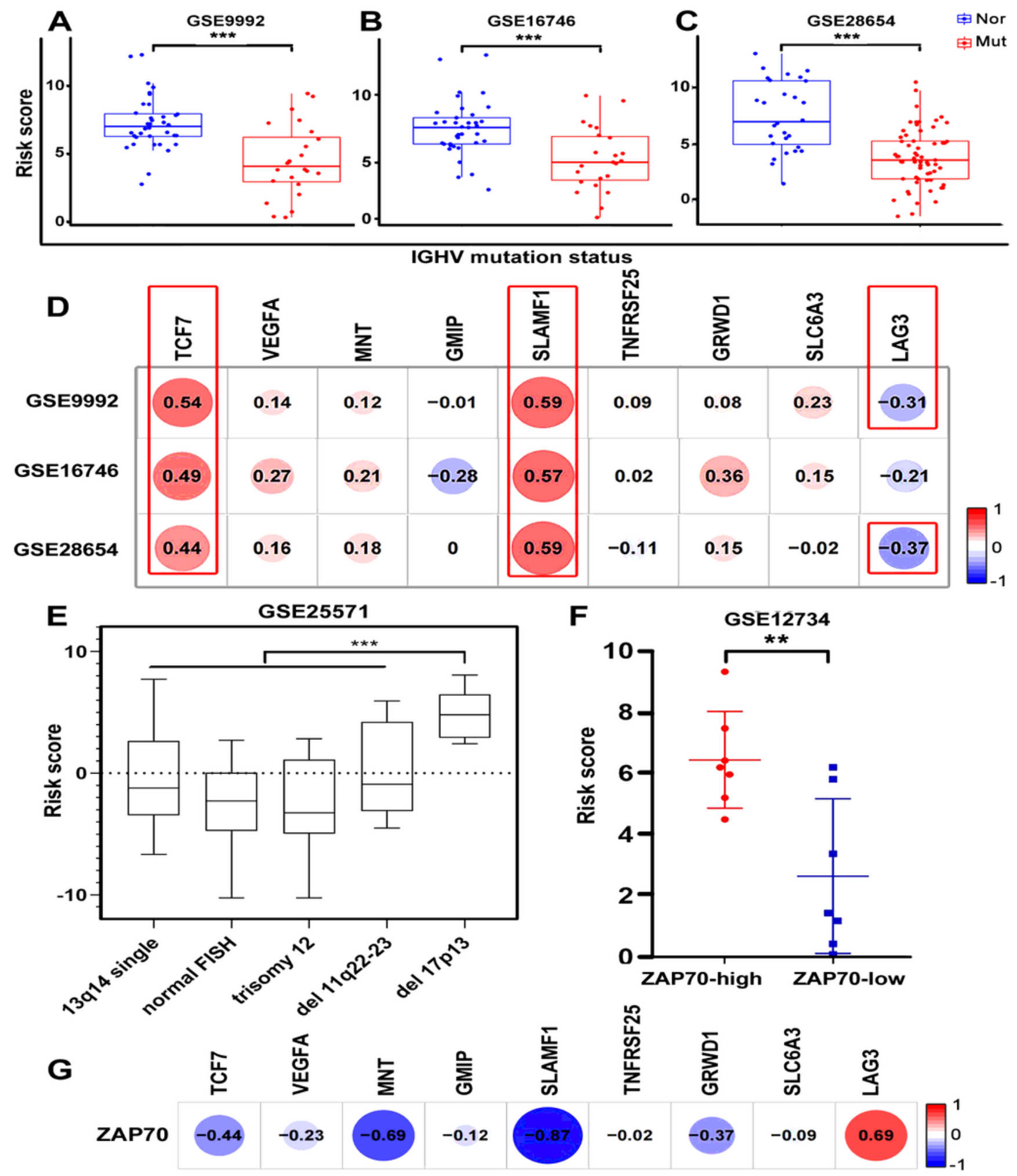

\section{Figure 8}

Correlation and variances between the risk score or each gene expression and well-established prognostic markers of CLL. (A)(B)(C)The risk score of patients with IGHV mutation was significant lower than patients without mutation in GSE9992, GSE16746 and GSE28654. Nor, normal; Mut, mutation. (D) The correlation analysis of nine hub genes expression and IGHV mutation statue. The p-value in red box $<0.001$ respectively. $(E)$ The risk score of patients with del17p13 was significantly higher than other 
chromosome abnormalities. ${ }^{* \star}, p<0.001 .(F)(G)$ The different level of risk score in high- and low-ZAP70 patients and the correlation between nine hub genes expression and ZAP70 level.

\section{Supplementary Files}

This is a list of supplementary files associated with this preprint. Click to download.

- Additionalfile1.pdf 